\title{
Outpatient Cardiovascular Diseases and Diabetes Medicines Dispensing in the Population with Government Health Insurance in Syria Between 2018-2019: A Retrospective Analysis.
}

Saleh Aljadeeah ( $\nabla$ saleh.aljadeeah@uni-bayreuth.de )

University of Bayreuth

Eckhard Nagel

University of Bayreuth

Veronika J. Wirtz

Boston University School of Public Health

\section{Research Article}

Keywords: Non-communicable disease, Cardiovascular disease, Diabetes, Medicine, Insulin, Dispensing data, Demography, Syria, Conflict

Posted Date: August 5th, 2021

DOI: https://doi.org/10.21203/rs.3.rs-725149/v1

License: (c) (i) This work is licensed under a Creative Commons Attribution 4.0 International License. Read Full License 


\section{Abstract}

\section{Background:}

Low- and middle-income countries bear the highest burden of non-communicable diseases (NCDs) mortality and morbidity. Syria has undergone an epidemiological transition from infectious diseases to NCDs in the past decades. Despite the high prevalence of cardiovascular diseases (CVDs) and diabetes in Syria, little is known about medicines utilization or prescriptions for these diseases. The aims of this study are to present the patterns and rates of dispensing medicines used for CVDs and diabetes among patients with government health insurance in Syria and examine age, sex, and regional variation in the dispensing of these medicines.

\section{Methods}

Outpatient data from June 2018 to May 2019 on dispensed medicines for 81,314 adults with government health insurance were obtained. The dispensing rate was expressed as the number of defined daily doses (DDDs) per 1,000 beneficiaries per day (DID). The number of DIDs was adjusted according to beneficiaries' sex, age, and governorate.

\section{Results}

Beneficiaries received 337.75 DIDs of CVDs medicines and 35.66 DIDs of diabetes medicines, including 0.96 DID of insulin. CVDs and diabetes medicine dispensing rates were low during the study period and included very low rates of insulin dispensing. There were lower dispensing rates of CVDs and diabetes medicines among female beneficiaries. In addition, there were lower rates of CVDs and diabetes medicines and very low to no dispensing of insulin in some governorates that were only partly controlled by the Syrian government.

\section{Conclusions}

Additional efforts are needed to raise awareness about the prevention and management of CVDs and diabetes especially among females in Syria and consider cultural issues that might influence access to healthcare services. There is a crucial need to address the political and geographical challenges caused by the conflict which have limited access to CVDs and diabetes medicines in some regions in Syria.

\section{Background}

Non-communicable diseases (NCDs) account for $71 \%$ of all deaths globally. Seven NCDs were in the top ten causes of death in 2019 where cardiovascular diseases (CVDs) and diabetes are listed among the four leading causes of death globally [1, 2]. Low- and middle-income countries (LMICs) bear the highest burden of NCDs mortality and morbidity [3]. In particular, CVDs and diabetes are underdiagnosed and undertreated in LMICs and result in considerable morbidity and mortality [4]. In 2019, 463 million people were living with diabetes worldwide, with approximately $80 \%$ of those with the disease living in LMICs [5]. Similarly, over $75 \%$ of deaths caused by CVDs in 2019 occurred in LMICs [6]. It is estimated that this disease burden will continue to rise and cause financial burdens on health systems and households, particularly in LMICs [3].

Syria has undergone an epidemiological transition from infectious diseases to NCDs in the past decades. Before the conflict, NCDs (mainly CVDs, cancer, and diabetes) accounted for $77 \%$ of total mortality in the country $[7,8]$, with CVDs estimated to account for $25 \%$ of all deaths in 2016 in Syria [9]. Since 1980, the prevalence of diabetes in 
Syria has nearly tripled, to reach a total of $11.9 \%$ in 2016 [10]. During periods of conflict, people with chronic diseases such as diabetes face numerous challenges, including inadequate access to medicines and testing supplies, and food insecurity [11].

The year 2021 marks the tenth anniversary of the conflict in Syria. The conflict has resulted in one of the largest humanitarian crises in the world, with 6.6 million refugees worldwide, of whom 5.6 million are hosted in nearby countries, 6.7 million internally displaced persons, and 13.4 million people in need of humanitarian and protective assistance within the country $[12,13]$. Approximately $70 \%$ of health workers have fled Syria since the start of the conflict. Furthermore, nearly 600 attacks on healthcare facilities have led to approximately $50 \%$ of them being damaged or destroyed [14]. Healthcare during humanitarian crises have typically focused on infectious diseases and other acute conditions, with lower priority given to chronic diseases. However, chronic conditions such as CVDs and diabetes are now receiving more attention as many humanitarian crisis are no longer of short duration [11].

Healthcare in Syria is mainly financed by public funds, although, the costs of outpatient consultations and medicines are commonly covered by out-of-pocket expenditures [15]. There is no national health insurance that covers all inhabitants in the country. However, individuals working in public organizations, some ministries, and in professional associations are provided with health insurance [16]. This includes employees who occupy a variety of positions such as public school teachers, administrative staff, and janitors. A total of 841,852 individuals were covered by health insurance in Syria in 2019 , with approximately $80 \%$ of the insured employed by the government [17]. The diagnoses and treatment of CVDs and diabetes are covered by government health insurance, however, the treatment costs of some chronic conditions such as Alzheimer's or Parkinson's are not. Moreover, health insurance does not cover the costs for the treatment of psychiatric illnesses or sexually transmitted diseases [18].

The prevention and control of CVDs and diabetes usually require lifestyle changes. However, pharmacological therapies are also key elements for their management $[19,20]$. Diabetes, in particular, is a costly disease to manage in LMICs [21]. Globally, one in two people with type-2 diabetes have no access to the insulin they need; however, in some LMICs, this proportion is only one in six to seven patients have access to insulin [22]. The survival of 400,000 diabetic patients in Syria depends on access to insulin. Thus, due to limited supplies, approximately $60 \%$ of insulindependent patients are at risk $[10,11,23]$. Even when medicines are available during humanitarian crises and in conflict regions, their distribution can be challenging due to political and geographical barriers [11].

Previous studies have reported different utilization patterns for CVDs and diabetes medicines in different countries $[24,25]$. Furthermore, differences between males and females in the treatment of CVDs have been identified [26]. Despite the high prevalence of CVDs and diabetes in Syria, little is known about medicines utilization or prescriptions for these diseases [27]. Therefore, the aims of this study are to: 1) present the patterns and rates of dispensing medicines used for CVDs and diabetes among patients with government health insurance in Syria, and 2) examine age, sex, and regional variation in the dispensing of these medicines.

\section{Methods}

\section{Data sources and patients}

This study is based on outpatient medicines dispensing data from 13 out of 14 Syrian governorates. No data were available from the Ar-Raqqa governorate, which was not under the control of the Syrian government. We used health insurance data from 81,314 adult beneficiaries employed by the Syrian government and covered by the health insurance scheme, members of professional organizations, and university students who were privately insured. The 
data covered a 12-month period starting from June 2018. Outpatient dispensing data included the following information regarding each dispensed medicine: product name, dose, pharmaceutical form, and administration route. Additional information shared by the health insurance company were used to identify the international nonproprietary name of each product. In addition, the data included information on the age and sex of each beneficiary, the dispensing date, prescription number, and the name of the governorate where the medicine was dispensed.

\section{Data analysis}

We used the World Health Organization's (WHO's) anatomical therapeutic chemical classification/defined daily dose (ATC/DDD) (version 2020) methodology to analyse the dispensed medicines. The defined daily dose (DDD) is "the assumed average maintenance dose per day for a drug used for its main indication in adults" [28]. The rate of dispensed medicine was expressed as the DDD per 1,000 beneficiaries per day (DID). Medicines have been grouped using the ATC classification. In this study, CVD medicines included those from ATC groups C (cardiovascular system) and B01 (antithrombotic agents). Diabetes medicines included medicines from ATC group A10 (drugs used for diabetes). Medicine dispensing is presented according to the anatomical main group (ATC1), the therapeutic subgroup (ATC2), the pharmacological subgroup (ATC3), and the chemical substance subgroup (ATC5). We used the drug utilization $90 \%$ (DU90\%) methodology to reflect the number of medicines that accounted for $90 \%$ of the dispensing rates for CVD and diabetes medicines [29]. The number of DIDs was adjusted according to patient sex and age.

To adjust the number of DIDs according to regions or states, studies from Germany and Hungary have calculated the number of DDDs per 1,000 inhabitants of each region per day [30,31]. This analysis assumed that in these stable and high-income countries, the inhabitants of any region or state would have access to the medicines in that same region or state where they live. In Syria, the disruption of healthcare in some parts of the country due to the conflict has forced patients to flee their homes to other parts of the country to access better healthcare [32]. Our data showed that some beneficiaries had medicines for CVDs and diabetes dispensed in more than one governorate. Therefore, adjusting CVDs and diabetes medicines dispensing rates according to governorates by calculating the number of DDDs per 1,000 inhabitants (of each governorate) per day can be misleading. The CVDs and diabetes medicines dispensing rates were adjusted according to governorates by calculating the number of DDDs per 1,000 medicine dispensing events per day (DDED) [33]. The medicine dispensing events here refers to the dispensing of CVDs or diabetes medicines.

\section{Statistical analysis}

The dispensing data in this study displayed evidence of a skewed distribution. Therefore, statistical significance differences between the variables of interest were assessed using nonparametric testing. The Mann-Whitney $U$ test was used to analyze differences between the medians of the medicine dispensing rates between females and males. The Kruskal-Wallis nonparametric ANOVA was used to examine differences between the different age groups and governorates in regard to medicine dispensing rates. We considered a p-value of 0.05 as a cut-off value for significance in all the tests. Analyses were conducted using IBM SPSS Statistics version 25 (IBM Corp, Armonk, NY, USA).

\section{Results}

This study used the outpatient medicine dispensing data of 81,314 adult beneficiaries who were at least 18 years of age and covered by government health insurance in Syria. The median age of the beneficiaries was 47 years (interquartile range: $37-56)$, and 50,673 beneficiaries (62.28\%) were female and $30,671(37.72 \%)$ were male. Table 
1 lists the characteristics of the study population. The median age of the beneficiaries in Damascus, Aleppo, and Quneitra were the lowest, while the highest median age occurred in Tartous, Latakia, and Al-Suwayda (Additional file1)

Table 1

Characteristics of the study population by age and sex.

\begin{tabular}{|lllllll|}
\hline Age group & Female & \multicolumn{3}{c}{ Male } & \multicolumn{3}{c|}{ Total } \\
\cline { 2 - 7 } & $\mathbf{n}$ & $\%$ & $\mathbf{n}$ & $\%$ & $\mathbf{n}$ & $\%$ \\
\hline $18-29$ & 5,257 & 6.46 & 2,861 & 3.52 & 8,118 & 9.98 \\
\hline $30-39$ & 13,180 & 16.21 & 4,603 & 5.66 & 17,783 & 21.87 \\
\hline $40-49$ & 12,372 & 15.22 & 8,299 & 10.21 & 20,671 & 25.43 \\
\hline $50-59$ & 13,189 & 16.22 & 8,741 & 10.75 & 21,930 & 26.97 \\
\hline $60-69$ & 5,733 & 7.05 & 4,311 & 5.30 & 10,044 & 12.35 \\
\hline $70<=$ & 912 & 1.12 & 1,856 & 2.28 & 2,768 & 3.40 \\
\hline Total & 50,643 & 62.28 & 30,671 & 37.72 & 81,314 & 100 \\
\hline
\end{tabular}

Of the total number of beneficiaries, 46,281 (56.92\%) received at least one medicine in the 12-month period from June 2018 to May 2019. The total number of DIDs dispensed for these patients was 591.21. Considering the number of DIDs, medicines in anatomical main group C (the cardiovascular system) of the ATC classification system were the most dispensed, followed by those in group A (the alimentary tract and metabolism) (Additional file 2).

A total of 14,523 patients (17.84\%) received 337.75 DIDs of medicines used for cardiovascular system (C) and antithrombotic agents (B01). Medicines in the ATC therapeutic subgroup B01 (antithrombotic agents) were the most dispensed medicines (90.54 DIDs) followed by C10 (lipid-modifying agents; 83.64 DIDs) and C09 (renin-angiotensin system agents; 64.48 DIDs) (Table 2). 
Table 2

Outpatient dispensing rates of CVDs medicines according to the therapeutic subgroup (ATC2).

\begin{tabular}{|c|c|c|c|c|c|}
\hline & $\begin{array}{l}\text { Therapeutic subgroup } \\
\text { (ATC2) }\end{array}$ & $\begin{array}{l}\text { DID } \\
(n)^{*}\end{array}$ & $\begin{array}{l}\text { DID } \\
(\%)\end{array}$ & $\begin{array}{l}\text { Number of } \\
\text { patients }\end{array}$ & $\begin{array}{l}\text { Proportion of } \\
\text { patients }(\%)\end{array}$ \\
\hline \multirow{10}{*}{$\begin{array}{l}\text { Cardiovascular diseases } \\
\text { medicine }\end{array}$} & Antithrombotic agents (B01) & 90.54 & 15.31 & 9,433 & 11.60 \\
\hline & $\begin{array}{l}\text { Lipid-modifying agents } \\
\text { (C10) }\end{array}$ & 83.64 & 14.15 & 8,765 & 10.78 \\
\hline & $\begin{array}{l}\text { Renin-angiotensin system } \\
\text { agents (C09) }\end{array}$ & 64.48 & 10.91 & 8,377 & 10.30 \\
\hline & Beta-blocking agents (CO7) & 30.48 & 5.16 & 6,543 & 8.05 \\
\hline & $\begin{array}{l}\text { Calcium-channel blockers } \\
\text { (C08) }\end{array}$ & 14.35 & 2.43 & 2,031 & 2.48 \\
\hline & Cardiac therapy (C01) & 9.26 & 1.57 & 1,438 & 1.77 \\
\hline & Diuretics (C03) & 8.12 & 1.37 & 1,336 & 1.64 \\
\hline & Antihypertensives (C02) & 1.00 & 0.17 & 334 & 0.41 \\
\hline & $\begin{array}{l}\text { Peripheral vasodilators } \\
\text { (CO4) }\end{array}$ & 0.18 & 0.03 & 230 & 0.28 \\
\hline & Vasoprotectives (C05) & 0.04 & 0.01 & 2,441 & 3.00 \\
\hline
\end{tabular}

A total of 4,466 patients (5.49\%) received 35.66 DIDs of diabetes medicines (medicines used in diabetes: A10). Medicines in the pharmacological subgroup A10B (blood glucose lowering drugs, excluding insulin; $34.70 \mathrm{DIDs}$ ) were the most dispensed among diabetes medicines, while 0.96 DID of the A10A group (insulin and analogues) were dispensed for diabetes patients (Table 3).

Table 3

Outpatient dispensing rates of diabetes medicines according to the pharmacological subgroup (ATC3).

\begin{tabular}{|lclll|}
\hline Therapeutic subgroup (ATC) & $\begin{array}{l}\text { DID } \\
(\mathbf{n})^{*}\end{array}$ & $\begin{array}{l}\text { DID } \\
(\%)\end{array}$ & $\begin{array}{l}\text { Number of } \\
\text { patients }\end{array}$ & $\begin{array}{l}\text { Proportion of patients } \\
\text { (\%) }\end{array}$ \\
\hline Insulin and analogues (A10A) & 0.96 & 0.16 & 117 & 0.14 \\
\hline $\begin{array}{l}\text { Blood glucose lowering drugs excluding } \\
\text { insulins (A10B) }\end{array}$ & 34.70 & 5.87 & 4,413 & 5.43 \\
\hline $\begin{array}{l}\text { *Outpatient medicines dispensing according to the pharmacological subgroup (ATC3) is expressed as the } \\
\text { number of defined daily doses (DDDs) per 1,000 people per day (DID). }\end{array}$ & \\
\hline
\end{tabular}

Acetylsalicylic acid was the most dispensed CVD medicine (60.84 DIDs) followed by rosuvastatin (47.56 DIDs) and clopidogrel (23.03 DIDs). Thirty medicines accounted for 272.92 DIDs, which were $90 \%$ of the total DIDs of the 
dispensed CVD medicines. Metformin was the most dispensed diabetes medicine (8.29 DIDs) followed by gliclazide (7.44 DIDs) and the fixed dose combination of metformin and sulfonylureas (6.82 DIDs). Eight medicines accounted for 32.76 DIDs, which were $91.86 \%$ of the total DIDs of the dispensed diabetes medicines (Additional file 3).

Of the 4,466 patients who received diabetes medicines, 117 (2.62\%) received 0.96 DID of insulin and analogues. Approximately $30 \%$ of the dispensed insulins were insulin analogues. Human insulin (intermediate- or long-acting combined with fast-acting insulin) was the most dispensed (0.55 DIDs) followed by insulin aspart (0.18 DIDs) and fast-acting human insulin (0.9 DIDs) (Table 4).

Table 4

Outpatient dispensing rates of insulin among adults with health insurance in Syria.

\begin{tabular}{|lllll|}
\hline Medicine (ATC5) & $\begin{array}{l}\text { DID* } \\
\text { (n) }\end{array}$ & $\begin{array}{l}\text { DID } \\
\text { (\%) }\end{array}$ & $\begin{array}{l}\text { Number of } \\
\text { patients }\end{array}$ & $\begin{array}{l}\text { Proportion of } \\
\text { patients (\%) }\end{array}$ \\
\hline $\begin{array}{l}\text { Insulin (human) intermediate- or long-acting combined } \\
\text { with fast-acting (A10AD01) }\end{array}$ & 0.55 & 0.09 & 67 & 0.08 \\
\hline $\begin{array}{l}\text { Insulin aspart (A10AD05) } \\
\text { Insulin (human) fast acting (A10AB01) }\end{array}$ & 0.18 & 0.03 & 25 & 0.03 \\
\hline Insulin lispro (A10AD04) & 0.09 & 0.01 & 10 & 0.01 \\
\hline Insulin glargine (A10AE04) & 0.08 & 0.01 & 12 & 0.01 \\
\hline Insulin (human) intermediate acting (A10AC01) & 0.04 & 0.01 & 9 & 0.01 \\
\hline *Dispensing rates of insulin are expressed as the number of defined daily doses per 1,000 people per day (DID). \\
\hline
\end{tabular}

We found that $16.12 \%(8,384)$ of female beneficiaries and $19.66 \%(6,141)$ of male beneficiaries received outpatient CVDs medicines. The adjusted DID rates of CVDs medicines were higher among male patients (388.80 DIDs) than female patients (249.59 DIDs). A statistically significant difference was observed in CVDs medicine dispensing rates between female and male patients $(p<0.001)$. Among both females and males, the CVDs medicines in the ATC therapeutic subgroup B01 (antithrombotic agents) were the most dispensed followed by C10 (lipid-modifying agents) and C09 (renin-angiotensin system agents) (Figure 1). We found that $4.91 \%(2,489)$ of the female beneficiaries and $6.45 \%(1,977)$ of the male beneficiaries received outpatient diabetes medicines. The adjusted DID rates of diabetes medicines were higher among males (45.98 DIDs) than females (29.42 DIDs). A statistically significant difference was observed in the diabetes medicine dispensing rates between female and male patients $(p<0.001)$. The adjusted DID rates for insulins were also higher among male patients in comparison to females (1.14 DIDs and 0.85 DIDs, respectively).

For beneficiaries in the age group 18-29, 3.76\% received CVDs medicines. The proportion of patients who received CVDs medicines increased with age and was $50.53 \%$ in the $70<=$ age group. The adjusted DID rates of CVDs medicines were the lowest in the 18-29 age group (1.80 DIDs) and increased to 1,229.04 DIDs in the 70<= age group. A statistically significant difference was observed in CVDs medicine dispensing rates between the different age groups $(p<0.001)$. The CVD medicines in the ATC therapeutic subgroup B01 (antithrombotic agents) were the most dispensed CVDs medicines followed by C10 (lipid-modifying agents) and C09 (renin-angiotensin system 
agents) in all age groups except in the 30-39 age group where the ATC therapeutic subgroup C10 (lipid-modified agents) were the most dispensed, followed by B01 (antithrombotic agents) (Figure 2).

Of the beneficiaries in the age group $18-29,0.58 \%$ received diabetes medicines. The proportion of patients who received diabetes medicines increased with age to $21.46 \%$ in the $70<=$ age group. The adjusted DID rates of diabetes medicines were the lowest among patients in the 18-29 age group (0.28 DIDs) and increased to 131.34 DIDs in the $70<=$ age group (Figure 3 ). A statistically significant difference was observed in diabetes medicine dispensing rates between the different age groups $(p<0.001)$.

We found a statistically significant difference $(p<0.001)$ in CVDs medicine dispensing rates between Syria's different governorates. According to the number of DDEDs in each governorate, the Damascus countryside (1,655.03 DDED), Latakia (1,203.21 DDEDs), and Tartous (998.37 DDEDs) had the highest CVDs medicine dispensing rates, while Deer el-Zour (39.38 DDED), Idlib (45.71 DDEDs), and Quneitra (120.69 DDEDs) had the lowest CVDs medicine dispensing rates (Figure 4).

In terms of diabetes medicine dispensing rates, the difference between Syria's different governorates was statistically significant ( $p<0.001)$. The Damascus countryside (205.23 DDEDs), Latakia (147.75 DDEDs), and Tartous (127.11 DDEDs) had the highest diabetes medicine dispensing rates, while Idlib (1.01 DEDDs), Deer el-Zour (4.07 DDEDs) and Quneitra (15.61 DDEDs) had the lowest diabetes medicine dispensing rates (Figure 5). The highest insulin dispensing rates were recorded in the Damascus countryside (14.32 DDEDs), Latakia (6.85 DDEDs), and Al-Suwayda (6.74 DDEDs). The insurance data did not record insulin dispensing in the governorates of AlHasakah, Idlib, Deer el-Zour, or Daraa (Additional file 4).

\section{Discussion}

To the best of our knowledge, this is the first study to report CVDs and diabetes medicine dispensing at the population level in Syria using health insurance data from a large sample (81,314 beneficiaries) over a 12-month period. This study contributes to our knowledge regarding treatments for two common NCDs in Syria: CVDs and diabetes. Our analysis yielded three key findings: 1) CVDs and diabetes medicine dispensing rates were low during the study period and included very low rates of insulin dispensing; 2) there were lower dispensing rates of CVDs and diabetes medicines among female beneficiaries; and 3) there were higher rates of CVDs and diabetes medicines dispensed in governorates that were completely or mostly controlled by the government and very low to no dispensing of insulin in some governorates that were partly controlled by the Syrian government.

The rates for dispensing cardiovascular system medicines (C) were the highest in comparison to the other medicine groups. This can be explained by the high rate of CVDs in Syria [35]. CVDs medicine dispensing rates in our study were, however, low compared to many other countries. A study from Australia reported higher rates of dispensed CVD medicines (566.00 DIDs) [36], and a study from Serbia reported higher dispensing rates for some antihypertensives as well (283 DIDs) [37]. These differences in medicine use between countries may be the result of differences in the age and sex distribution of the populations, differences in the prevalence of high blood pressure and cholesterol, and variation in clinical practices [38]. Other reasons for the low dispensing rates of CVDs medicines found in this study could be associated with the ongoing conflict in Syria. Access to medicines, including CVDs medicines, can be affected by several barriers, including travel bans and checkpoints during conflict [39].

Antithrombotic medicines were the most dispensed group among the CVDs medicines. Antithrombotic drugs, which include antiplatelet and anticoagulant therapies, prevent and treat a number of cardiovascular disorders and are 
some of the most commonly prescribed drugs globally [40]. The high rate of antithrombotic medicines included acetyl salicylic acid, which accounted for $67.20 \%$ of the antithrombotic medicine rates and was the most dispended CVDs medicine. Acetyl salicylic acid is the most prescribed antiplatelet medicine for CVDs prevention in many countries [40].

The dispensing rate of diabetes medicine in Syria was 35.66 DIDs. This rate is quite low compared to those in other countries. A study that reported on the consumption of antidiabetic medicine in the 28 countries of the Organization for Economic Co-operation and Development (OECD) found that the average rate of diabetes medicine consumption was 68 DIDs, which is nearly double the rate found in our study. Similarly, in neighboring Turkey the consumption rate of diabetes medicine is 73 DIDs, which is more than double the rate we found in our study [41]. Another study reported that the rate of diabetic medicine consumption in Iran in 2012 was also low in comparison to other countries (33.54 DIDs) [24]. However, this rate may have increased in the years 2018-2019 to exceed the rate of diabetes medicine consumption in our study, as the authors of that report indicated an ongoing increase in diabetes medicine rates with time in Iran. The low dispensing rates of diabetic medicine that we found could be related to a potentially high number of undiagnosed diabetes in Syria. The WHO has reported that four in five undiagnosed diabetic patients live in LMICs [42]. One study has reported that diabetes was well controlled in only $16.7 \%$ of type-2 diabetes patients in Aleppo in 2011-before the start of the conflict [43]. Since there is evidence on the low number of controlled diabetes cases it would be expected that there is a low rate of diabetes medicines utilization. In addition, the low dispensing rates of diabetes medicines may be explained by factors related to the conflict situation in Syria. A study conducted among a group of diabetes patients in main public hospitals in Damascus during the Syrian crisis reported that $41.2 \%$ of the patients had stopped their medicines for at least one month over the course of seven years of conflict, and $74.8 \%$ of these patients attributed stopping their therapy to the unavailability of medicines. Furthermore, approximately half of the patients had to change their medicines brand names because many pharmaceutical companies closed due to the conflict. In addition, half of the diabetic patients struggled to reach a healthcare center [44]. Moreover, food insecurity in countries affected by conflict limits the possibility of diabetes patients to adhere to recommended diets, which would present an obstacle to maintaining treatment as diabetes medicines must be taken with food [45].

A total of $97.31 \%$ of the dispensed diabetes medicines were oral. Metformin, a first-line treatment for type-2 diabetes [46], was the most common medicine. This is in line with studies that have reported metformin as the most commonly dispensed diabetes medicine in many countries [47-49]. We found an insulin dispensing rate of 0.96 DID. Higher rates of insulin prescriptions in other counties has been reported. For instance, a study from Albania reported a 5.64 DIDs insulin outpatient prescription rate [49], while Iran reported higher insulin consumption rates in 2012 (5.73 DIDs) [24]. A study from Portugal reported an insulin dispensing rate of 15.1 DIDs in 2014. In addition to the factors we have previously mentioned to explain the low dispensing rates of diabetes medicine, specific factors related to insulin could also explain the low rates. The limited availability of insulin due to the conflict in the country may be another factor. Approximately $60 \%$ of insulin-dependent Syrians are at risk due to limited supplies [11, 23]. Furthermore, insulin requires cold-chain transportation and the maintenance of temperatures between $2^{\circ} \mathrm{C}$ and $8^{\circ} \mathrm{C}$. The storage of insulin by patients is an additional challenge as the lack of refrigeration is common due to frequent energy cuts [11]. In addition, our data may not include all of the insulin given to insulin-dependent diabetic patients, as they could have received insulin through other channels such as humanitarian organizations-the WHO is now the main supplier of insulin in Syria [23]. Poor adherence to insulin caused by injection phobia among some patients has been recorded in other studies [45]. This can also further explain the very low rates of insulin dispensing in our study. 
CVDs medicine dispensing rates were significantly higher among males than females (388.80 DIDs and 249.59

DIDs, respectively). Other studies have reported higher rates of hypertension among middle-aged females (35 to 65 years) than males in Syria and other countries of the Eastern Mediterranean region and North Africa [50]. Moreover, women of Arab ethnicity present with coronary artery disease ten years earlier than those from Europe or East Asia [51]. Obesity, a significant risk factor of CVDs, also has a higher prevalence among females in Eastern Mediterranean region countries, including Syria $[35,52,53]$. Cultural and religious norms, as well as circumstances related to the conflict and lack of security, restrict women from sports and limit physical activity. These factors may also contribute to the CVDs burden among women in Syria and the region [51]. The lower dispensing rates of CVDs medicines among females in our study contrasts with other studies that have reported higher rates of CVDs in females in Syria. This suggests that CVDs were undertreated among females in our study population. Despite being the leading cause of death among women globally, CVDs in women are still understudied, underdiagnosed, and undertreated [54]. There is a common misperception that CVDs affect men more than women, and this may contribute to the suboptimal treatment of CVDs among women [26]. Similar to CVDs, the dispensing rates of diabetes medicines, including insulin dispensing rates, were significantly higher among males than females (45.98 DIDs and 29.42 DIDs, respectively); however, the WHO has reported a higher prevalence of diabetes among females in Syria than males (12.6\% and $11.2 \%$, respectively) [23]. This result indicates the undertreatment of diabetes among females in our study. Other studies have reported poorer control of type-2 diabetes among women than men [55-57]. Furthermore, the conflict situation in Syria may have contributed to women's vulnerability in comparison to men. The crisis has restricted women's movement more than men and limited their access to healthcare, including diabetic care $[11,58]$. Unsurprisingly, the dispensing rates of CVDs and diabetes medicines increased with increasing age, which is due to the increasing prevalence of CVDs and diabetes with increasing age $[59,60]$.

There was a significant difference in the dispensing rates of CVDs and diabetes medicines between the different governorates in Syria. The Damascus countryside, Latakia, and Tartous had the highest dispensing rates for CVDs and diabetes medicines, while Idlib, Deer el-Zour, and Quneitra had the lowest rates. The major areas of the three governorates with the highest CVDs and diabetes medicines dispensing rates (Damascus countryside, Latakia, and Tartous) were under the Syrian government's control. However, while the major areas of Deer el-Zour and Idlib were out of the Syrian government's control, they were affected by the armed conflict during the study period [61]. This regional variation may be related to the conflict situation that has rendered services damaged or unavailable. There is an uneven distribution of healthcare services, including medicines, across geographical regions [62, 63]. Through internal displacement, the conflict has also contributed to regional variation in Syrian healthcare services. The disruption of healthcare in some parts of Syria has forced patients with chronic diseases, especially older individuals, to flee their homes to other parts of the country to access better healthcare [32]. Our data did not record insulin dispensing in Al-Hasakah, Idlib, Deer el-Zour, and Daraa. Being a cold chain product, delivery of insulin in these regions may have been extremely challenging. The distribution of essential medicines, including insulin even when it was available, can be complex due to geographical and political barriers [11]. Thus, insulin-dependent diabetes patients may have relied on private funding or the assistance of humanitarian organizations to access insulin.

\section{Strengths and limitations}

The study's limitations principally arose from the data that was used, as it did not provide the diagnoses underlying the prescribed medicines. The generalizability is also limited as our data only included people with government health insurance. The majority of our study population were employed by the Syrian government. Government employees in Syria belong usually to the country's middle-income class [64]. The study did not include people living 
in areas of Syria that were out of government control. In particular, the number of insured people in Deer el-Zour and Idlib was significantly lower than other governorates because large areas of these regions were beyond the Syrian government's control. Further studies are necessary to reach those regions. Our data did not necessarily include all the diabetes medicines used by diabetic patients because some might receive these medicines, especially insulin, through other sources such as humanitarian organizations. Despite these limitations, our study represents an essential step towards understanding medicine use for NCDs such as CVDs and diabetes in a country plagued by an ongoing conflict since 2011. Our research also provides a picture of CVD and diabetes management in a large sample that is diverse in terms of age and sex and included data on medicine use in 13 out of 14 Syrian governorates. Finally, reporting medicine dispensing rates and patterns using ATC/DDD methodology enables the comparison of medicine dispensing at the international level [65].

\section{Conclusions}

This study presents the first estimates of CVDs and diabetes medicines dispensing rates and patterns at population level in Syria using health insurance data from a large sample (81,314 beneficiaries) over 12 months. Our study demonstrated significant difference in CVDs and diabetes medicines dispensing rates between male and female beneficiaries. This study also showed significant regional variation in CVDs and diabetes medicines dispensing with lower CVDs and diabetes medicines dispensing rates and very low to no dispensing of insulin in some governorates that the Syrian government partly controlled. Additional efforts are needed to raise awareness about the prevention and management of CVDs and diabetes, especially among females in Syria including cultural issues that might influence access to healthcare services. In addition, the growing importance of NCDs during humanitarian crises should be recognized by all healthcare providers. Humanitarian healthcare workers should be trained to handle CVDs and diabetes emergencies. There is a crucial need to address the political and geographical challenges caused by the conflict in Syria, limiting access to CVDs and diabetes medicines in some regions in Syria. It is the responsibility of the Syrian government and the other different actors across the country to ensure continuous access to healthcare services, including essential medicines, to the population in the different regions of Syria. We encourage further research that would address CVDs, and diabetes medicines use in the areas beyond the control of the Syrian government.

\section{Abbreviations}

ATC, Anatomical Therapeutic Chemical Classification

CVD, Cardiovascular Disease

DDD, Defined Daily Dose

DDED, Defined Daily Dose Dispensing Events per Day

DED, Dispensing Events per Day

DID, Defined Daily Dose per 1,000 beneficiaries per day

DU90\%, Drug Utilization 90\%

LMICs, Low- and Middle-Income Countries

Page $11 / 21$ 
NCD, Non-Communicable Disease

OECD, Organization for Economic Co-operation and Development

WHO, World Health Organization

\section{Declarations}

\section{Ethics approval and consent to participate}

Individual patients could not be identified through the information in the dispensing data used in this study. The ethics committee of the University of Bayreuth stated that the analysis and reporting of the dispensing data in this study did not require their approval. This study is an anonymized, secondary data analysis study; no consent to participate was necessary.

\section{Consent for publication}

Not applicable.

\section{Availability of data and materials}

The datasets generated and analysed during the current study are not publicly available due a request from the data provider but are available from the corresponding author on reasonable request.

\section{Competing interests}

The authors declare that they have no competing interests.

\section{Funding}

This work was supported by a PhD fellowship from the Konrad Adenauer Foundation. (Grant number: 007346). The funder had no role in the design and conduct of the study, the analysis and interpretation of the data, or the preparation, review and approval of the manuscript. This publication was funded by the German Research Foundation (DFG) and the University of Bayreuth in the funding program Open Access Publishing.

\section{Authors' contributions}

Conceptualization, SA, EN and VJW; Methodology, SA, EN and VJW; Formal Analysis, SA and VJW; Data Curation, SA; Writing-Original Draft Preparation, SA; Writing-Review \& Editing, SA, EN and VJW; Supervision, EN and VJW. All authors critically revised the manuscript and approved the final version.

\section{Acknowledgments}

We greatly acknowledge the WHO Collaborating Centre for Drug Statistics Methodology for consulting us on coding our data.

\section{References}


1. World Health Organization: Noncommunicable diseases; 2021. Available from: https://www.who.int/newsroom/fact-sheets/detail/noncommunicable-diseases. Accessed on 06 Jun 2021.

2. Devi S: Aid agencies turn attention to diabetes. The Lancet 2021, 397:1049-1050.

3. Kankeu HT, Saksena P, Xu K, Evans DB: The financial burden from non-communicable diseases in low- and middle-income countries: a literature review. Health research policy and systems 2013, 11:31.

4. World Health Organization: GLOBAL ACTION PLAN FOR THE PREVENTION AND CONTROL OF NONCOMMUNICABLE DISEASES 2013-2020. Available from: https://apps.who.int/iris/bitstream/handle/10665/94384/9789241506236_eng.pdf? sequence=1\&isAllowed=y. Accessed on 02 Jun 2021.

5. Chan JCN, Lim L-L, Wareham NJ, Shaw JE, Orchard TJ, Zhang P, et al.: The Lancet Commission on diabetes: using data to transform diabetes care and patient lives. The Lancet 2020, 396:2019-2082.

6. World Health Organization: Cardiovascular diseases (CVDs). Available from: https://www.who.int/newsroom/fact-sheets/detail/cardiovascular-diseases-(cvds). Accessed on 12 Jun 2021.

7. Ansbro É, Homan T, Prieto Merino D, Jobanputra K, Qasem J, et al: Clinical outcomes in a primary-level noncommunicable disease programme for Syrian refugees and the host population in Jordan: A cohort analysis using routine data. PLoS medicine 2021, 18:e1003279.

8. World Health Organization: Noncommunicable diseases country profiles. Geneva, Switzerland: World Health Organization; 2011. Available from: file://C:/Users/asus/AppData/Local/Temp/9789241514620-eng.pdf. Accessed on 07 Jun 2021.

9. World Health Organization: Noncommunicable diseases country profiles. Available from: file://C:/Users/asus/AppData/Local/Temp/9789241514620-eng.pdf. Accessed on 07 June 2021.

10. World Health Organization: Diabetes country profiles. Available from: https://www.who.int/diabetes/countryprofiles/syr_en.pdf. Accessed on: 03 Jun 2021.

11. Khan Y, Albache N, Almasri I, Gabbay RA: The Management of Diabetes in Conflict Settings: Focus on the Syrian Crisis. Diabetes spectrum: a publication of the American Diabetes Association 2019, 32:264-269.

12. UNICEF: Syria Crisis. Humanitarian Situation ReportJanuary -December 2020. available from: https://www.unicef.org/media/96446/file/Syria-Crisis-Humanitarian-SitRep-December-2020.pdf. Accessed on 10 Jun 2021.

13. UNHCR: Syria emergency. 2021. Available from: https://www.unhcr.org/syria-emergency.html. Accessed on 26 May 2021.

14. Devi S: Health in Syria: a decade of conflict. The Lancet 2021, 397:955-956.

15. Sen K, Al Faisal W: Syria Neoliberal Reforms in Health Sector Financing: Embedding Unequal Access? Social Medicine 2012, 6:171-182.

16. Schwefel D: Towards a national health insurance system in Syria. Available from: http://detlefschwefel.de/246-Schwefel-Syria-health-insurance.pdf. Accessed on 30 May 2021.

17. Syrian Insurance Supervisory Commission.: Syrian Insurance Sector Report for 2019. Available from: http://www.sisc.sy/Publications/37/32/Ar. Accessed on 30 May 2021.

18. Syrian General Association for Insurance: Health Insurance Guide. available from: https://www.siceclaim.com/Assets/SIC/Docs/HealthcarelnsuranceGuide.pdf. Accessed on 11 Jun 2021.

19. Wirtz VJ, Kaplan WA, Kwan GF, Laing RO: Access to Medications for Cardiovascular Diseases in Low- and Middle-Income Countries. Circulation 2016, 133:2076-2085. 
20. Nathan DM, Buse JB, Davidson MB, Ferrannini E, Holman RR, Sherwin R, et al: Medical management of hyperglycemia in type 2 diabetes: a consensus algorithm for the initiation and adjustment of therapy: a consensus statement of the American Diabetes Association and the European Association for the Study of Diabetes. Diabetes care 2009, 32:193-203.

21. Moucheraud C, Lenz C, Latkovic M, Wirtz VJ: The costs of diabetes treatment in low- and middle-income countries: a systematic review. BMJ global health 2019, 4:e001258.

22. Basu S, Yudkin JS, Kehlenbrink S, Davies JI, Wild SH, Lipska KJ, et al: Estimation of global insulin use for type 2 diabetes, 2018-30: a microsimulation analysis. The Lancet Diabetes \& Endocrinology 2019, 7:25-33.

23. World Health Organization: WHO helps diabetes patients in Syria. Available from: https://www.who.int/newsroom/feature-stories/detail/who-helps-diabetes-patients-in-syria. Accessed on 07 Jun 2021.

24. Sarayani A, Rashidian A, Gholami K: Low utilisation of diabetes medicines in Iran, despite their affordability (2000-2012): a time-series and benchmarking study. BMJ open 2014, 4:e005859.

25. Jarari N, Rao N, Peela JR, Ellafi KA, Shakila S, Said AR, et al: A review on prescribing patterns of antihypertensive drugs. Clinical hypertension 2015, 22:7.

26. Zhao M, Woodward M, Vaartjes I, Millett ERC, Klipstein-Grobusch K, Hyun K, et al: Sex Differences in Cardiovascular Medication Prescription in Primary Care: A Systematic Review and Meta-Analysis. Journal of the American Heart Association 2020, 9:e014742.

27. Akl C, Akik C, Ghattas H, Obermeyer CM: The cascade of care in managing hypertension in the Arab world: a systematic assessment of the evidence on awareness, treatment and control. BMC public health 2020, 20:835.

28. WHO Collaborating Centre for Drug Statistics Methodology.: Anatomical Therapeutic Chemical (ATC)Classification System. Available from: https://www.whocc.no/atc_ddd_index/. Accessed on 01 Jun 2021.

29. Bergman U, Popa C, Tomson Y, Wettermark B, Einarson TR, Aberg H, et al: Drug utilization 90\%--a simple method for assessing the quality of drug prescribing. European journal of clinical pharmacology 1998, 54:113118.

30. Kern WV, With K de, Nink K, Steib-Bauert M, Schröder H: Regional variation in outpatient antibiotic prescribing in Germany. Infection 2006, 34:269-273.

31. Matuz M, Benko R, Doro P, Hajdu E, Nagy G, Nagy E, et al: Regional variations in community consumption of antibiotics in Hungary, 1996-2003. British journal of clinical pharmacology 2006, 61:96-100.

32. United Nations GA: Protection of and assistance to internally displaced persons: situation of internally displaced persons in the Syrian Arab Republic. Available from:

https://www.ohchr.org/Documents/Issues/IDPersons/A_67_931Syria_report.pdf. Accessed on 20 Jun 2021.

33. Aljadeeah S, Wirtz VJ, Nagel E: Outpatient Antibiotic Dispensing for the Population with Government Health Insurance in Syria in 2018-2019. Antibiotics (Basel, Switzerland) 2020, 9.

34. OpenStreetMap, 2021. Available from: https://www.openstreetmap.org.

35. Al Ali R, Rastam S, Fouad FM, Mzayek F, Maziak W: Modifiable cardiovascular risk factors among adults in Aleppo, Syria. International journal of public health 2011, 56:653-662.

36. Australian Institute of Health and Welfare: Medicines for cardiovascular disease. Canberra, ACT: Canberra; AlHW; 2017.

37. Tomas A, Tomić Z, Milijasević B, Ban M, Horvat O, Vukmirović S, et al: Patterns of prescription antihypertensive drug utilization and adherence to treatment guidelines in the city of Novi Sad. Vojnosanitetski pregled 2016, 73:531-537. 
38. Wilkins E, Wilson L, Wickramasinghe K, Bhatnagar P, Leal J, Luengo-Fernandez R, Burns R, et al: European Cardiovascular Disease Statistics 2017.

39. Leyh BM, Gispen ME: Access to Medicines in Times of Conflict: Overlapping Compliance and Accountability Frameworks for Syria. Health and Human Rights 2018, 20:237-250.

40. Mega JL, Simon T: Pharmacology of antithrombotic drugs: an assessment of oral antiplatelet and anticoagulant treatments. The Lancet 2015, 386:281-291.

41. OECD Health Statistics 2019: Figure 10.8. Anti-diabetic drug consumption, 2000 and 2017 (or nearest year). Avialable from: https://www.oecd-ilibrary.org/sites/43146d4b-en/index.html? itemld=/content/component/43146d4b-en. Accessed on 15 Jun 2021.

42. World Health Organization: Changing the game to improve availability and affordability of quality-assured insulin and associated devices. Available from: https://www.who.int/news/item/25-09-2020-changing-thegame-to-improve-availability-and-affordability-of-quality-assured-insulin-and-associated-devices. Accessed on 20 Jun 2021.

43. Albache N, Al Ali R, Rastam S, Fouad FM, Mzayek F, Maziak W: Epidemiology of Type 2 diabetes mellitus in Aleppo, Syria. Journal of diabetes 2010, 2:85-91.

44. Hamzeh A, Almhanni G, Aljaber Y, Alhasan R, Alhasan R, Alsamman MI, et al: Awareness of diabetes and diabetic retinopathy among a group of diabetic patients in main public hospitals in Damascus, Syria during the Syrian crisis. BMC health services research 2019, 19:549.

45. Murphy A, Biringanine M, Roberts B, Stringer B, Perel P, Jobanputra K: Diabetes care in a complex humanitarian emergency setting: a qualitative evaluation. BMC health services research 2017, 17:431.

46. Sanchez-Rangel E, Inzucchi SE: Metformin: clinical use in type 2 diabetes. Diabetologia 2017, 60:1586-1593.

47. Okoro RN, Nmeka C, Erah PO: Utilization study of antidiabetes medicines at a tertiary care hospital in Nigeria. Future Journal of Pharmaceutical Sciences 2018, 4:109-115.

48. Lu CY, Emmerick ICM, Stephens P, Ross-Degnan D, Wagner AK: Uptake of new antidiabetic medications in three emerging markets: a comparison between Brazil, China and Thailand. Journal of pharmaceutical policy and practice $2015,8: 7$.

49. Kakariqi L: TRENDS IN PRESCRIBING AND UTILIZATION OF ANTIDIABETIC DRUGS IN PRIMARY HEALTH CARE IN ALBANIA DURING 2004-2014. IJSM 2016, 2:77.

50. Akl C, Akik C, Ghattas H, Obermeyer CM: Gender disparities in midlife hypertension: a review of the evidence on the Arab region. Women's midlife health 2017, 3:1.

51. Vogel B, Acevedo M, Appelman Y, Bairey Merz CN, Chieffo A, Figtree GA, et al: The Lancet women and cardiovascular disease Commission: reducing the global burden by 2030. The Lancet 2021, 397:2385-2438.

52. Djalalinia S, Saeedi Moghaddam S, Sheidaei A, Rezaei N, Naghibi Iravani SS, Modirian M,: Patterns of Obesity and Overweight in the Iranian Population: Findings of STEPs 2016. Frontiers in endocrinology 2020, 11:42.

53. Weiderpass E, Botteri E, Longenecker JC, Alkandari A, Al-Wotayan R, Al Duwairi Q, et al: The Prevalence of Overweight and Obesity in an Adult Kuwaiti Population in 2014. Frontiers in endocrinology 2019, 10:449.

54. Mocumbi AO: Women's cardiovascular health: shifting towards equity and justice. The Lancet 2021, 397:23152317.

55. Tang YH, Pang SMC, Chan MF, Yeung GSP, Yeung VTF: Health literacy, complication awareness, and diabetic control in patients with type 2 diabetes mellitus. Journal of advanced nursing 2008, 62:74-83. 
56. Chiu C-J, Wray LA: Gender differences in functional limitations in adults living with type 2 diabetes: biobehavioral and psychosocial mediators. Annals of behavioral medicine: a publication of the Society of Behavioral Medicine 2011, 41:71-82.

57. Shalev V, Chodick G, Heymann AD, Kokia E: Gender differences in healthcare utilization and medical indicators among patients with diabetes. Public health 2005, 119:45-49.

58. Akik C, Semaan A, Shaker-Berbari L, Jamaluddine Z, Saad GE, Lopes K, et al: Responding to health needs of women, children and adolescents within Syria during conflict: intervention coverage, challenges and adaptations. Conflict and health 2020, 14:37.

59. Suastika K, Dwipayana P, Siswadi M, Tuty RA: Age is an Important Risk Factor for Type 2 Diabetes Mellitus and Cardiovascular Diseases. In Glucose Tolerance. Edited by Chackrewarthy S: InTech; 2012.

60. Rodgers JL, Jones J, Bolleddu SI, Vanthenapalli S, Rodgers LE, Shah K, et al: Cardiovascular Risks Associated with Gender and Aging. Journal of cardiovascular development and disease 2019, 6.

61. European Asylum Support Office: Syria Security Situation. Available from: https://coi.easo.europa.eu/administration/easo/PLib/11_2019_EASO_COI_Report_Syria_Security_situation.pdf. Accessed on 08 Jun 2021.

62. Ben Taleb Z, Bahelah R, Fouad FM, Coutts A, Wilcox M, Maziak W: Syria: health in a country undergoing tragic transition. International journal of public health 2015, 60 Suppl 1:S63-72.

63. Kherallah M, Alahfez T, Sahloul Z, Eddin KD, Jamil G: Health care in Syria before and during the crisis. Avicenna journal of medicine 2012, 2:51-53.

64. Syrian Economic Sciences Society: Employment and Livelihood Support in Syria: A Study Conducted for UNDP Syria by the Syrian Economic Sciences Society. Available from:

file://C:/Users/asus/AppData/Local/Temp/Employment\%20and\%20Livelihoods\%20study_English.pdf. Accessed on 11 Jul 2021.

65. WHO Collaborating Center for Drug Statistics Methodology: Purpose of the ATC/DDD system. Available from https://www.whocc.no/atc_ddd_methodology/purpose_of_the_atc_ddd_system/. Accessed on: 20 Jun 2021.

\section{Figures}




\begin{tabular}{|c|c|c|}
\hline \multicolumn{3}{|c|}{450} \\
\hline \multicolumn{3}{|c|}{400} \\
\hline \multicolumn{3}{|c|}{350} \\
\hline \multicolumn{3}{|c|}{300} \\
\hline & & \\
\hline & & \\
\hline \multicolumn{3}{|c|}{150} \\
\hline \multicolumn{3}{|c|}{100} \\
\hline \multicolumn{3}{|c|}{50} \\
\hline & Female & Male \\
\hline & - Antithrombotic agents (B01) & - Lipid modifying agents (C10) \\
\hline & 口 Renin-angiotensin system agents (C09) & " Beta-blocking agents (CO7) \\
\hline & 口 Calcium-channel blockers (C08) & - Cardiac therapy (C01) \\
\hline & - Diuretics (C03) & - Antihypertensives (CO2) \\
\hline & - Peripheral vasodilators (CO4) & - Vasoprotectives (C05) \\
\hline
\end{tabular}

Figure 1

Adjusted CVDs medicines dispensing rates (DID) according to the therapeutic subgroup (ATC2) by sex. 
1000

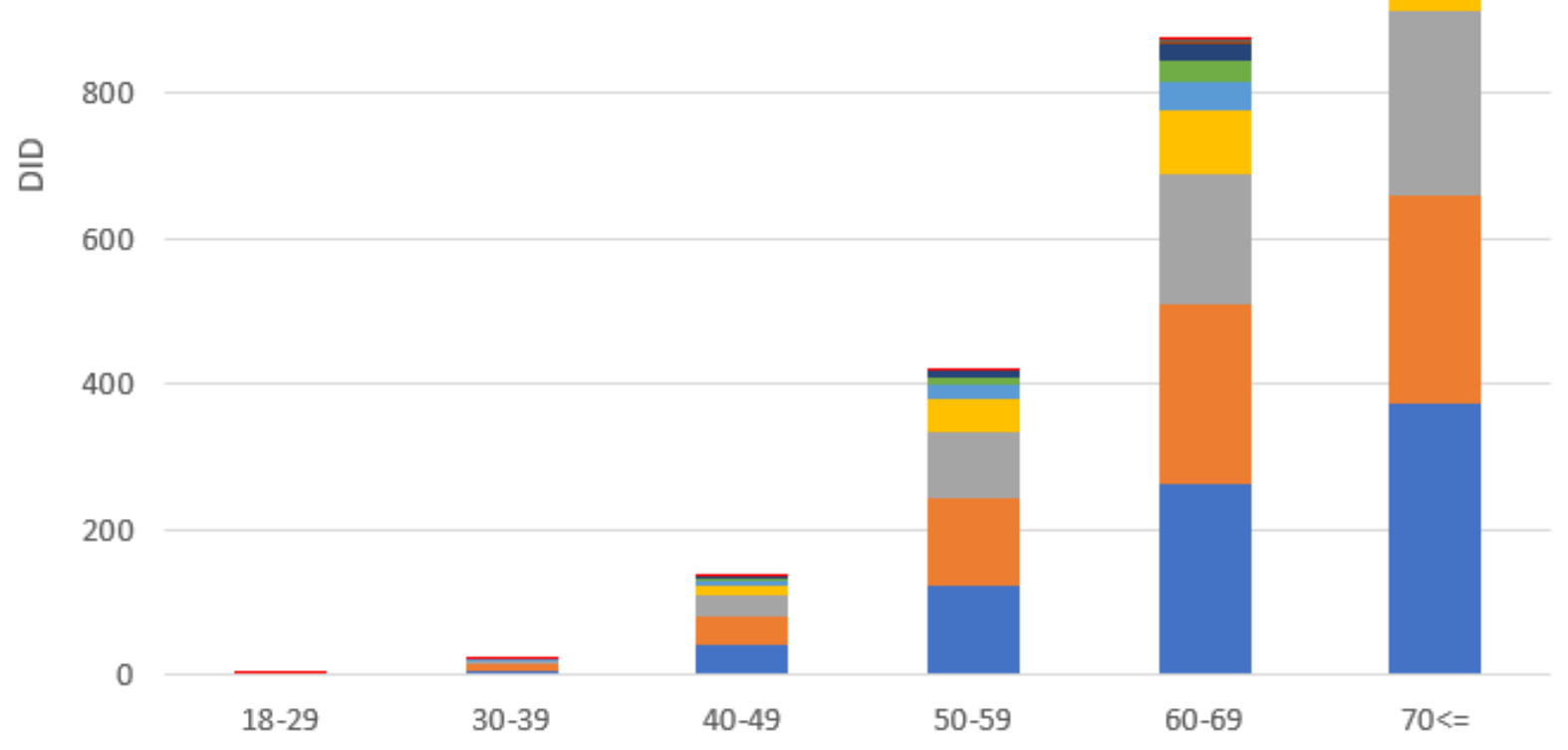

Antithrombotic agents (B01)

- Renin-angiotensin system agents (CO9)

- Calcium-channel blockers (C08)

- Diuretics (C03)

- Peripheral vasodilators (C04)
- Lipid modifying agents (C10)

aeta-blocking agents (C07)

- Cardiac therapy (CO1)

antihypertensives (CO2)

- Vasoprotectives (C05)

\section{Figure 2}

Adjusted cardiovascular system medicines dispensing rates (DDD) among adults with health insurance in Syria by age groups. 


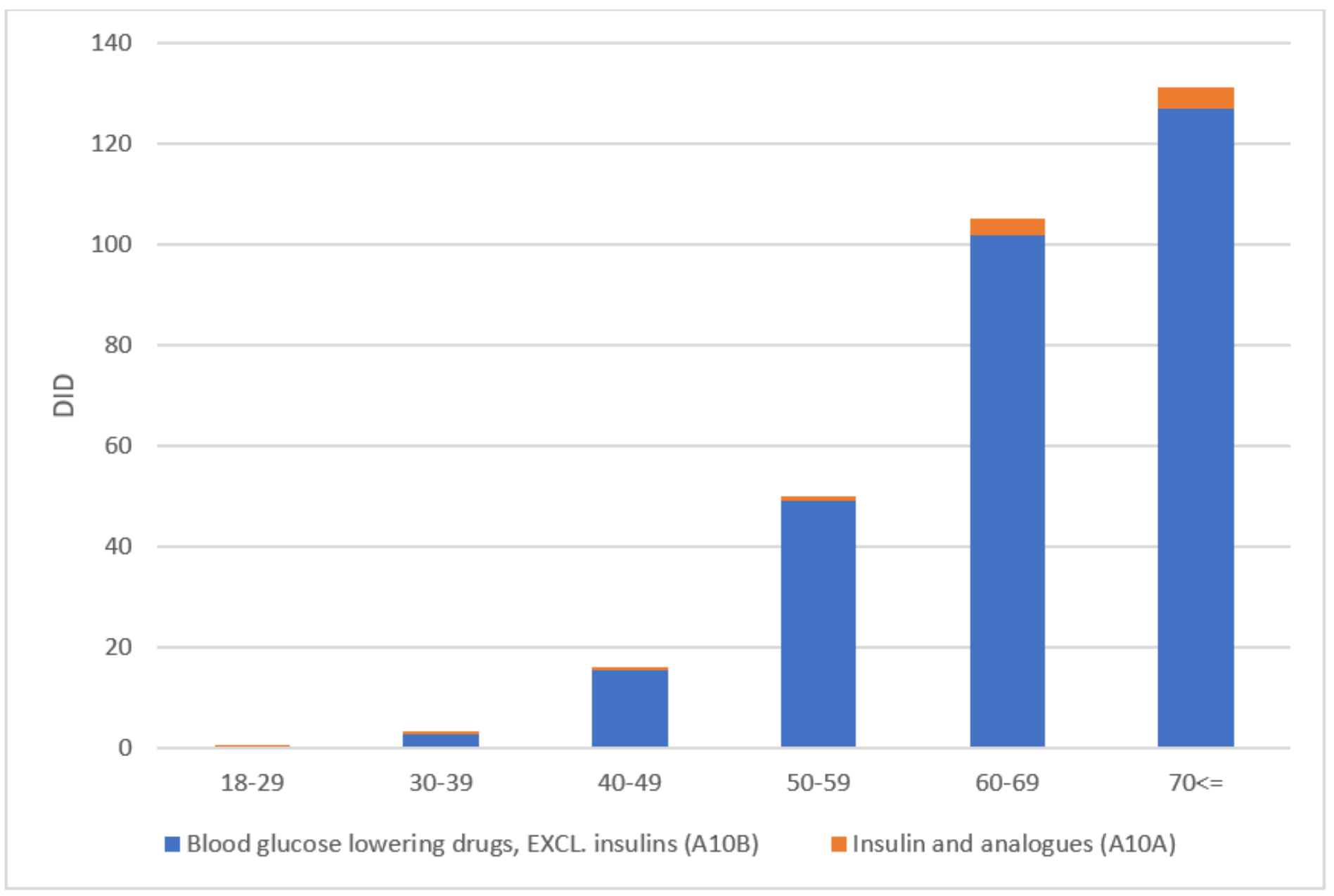

Figure 3

Adjusted diabetes medicines dispensing rates (DID) according to the pharmacological subgroup by age groups. 


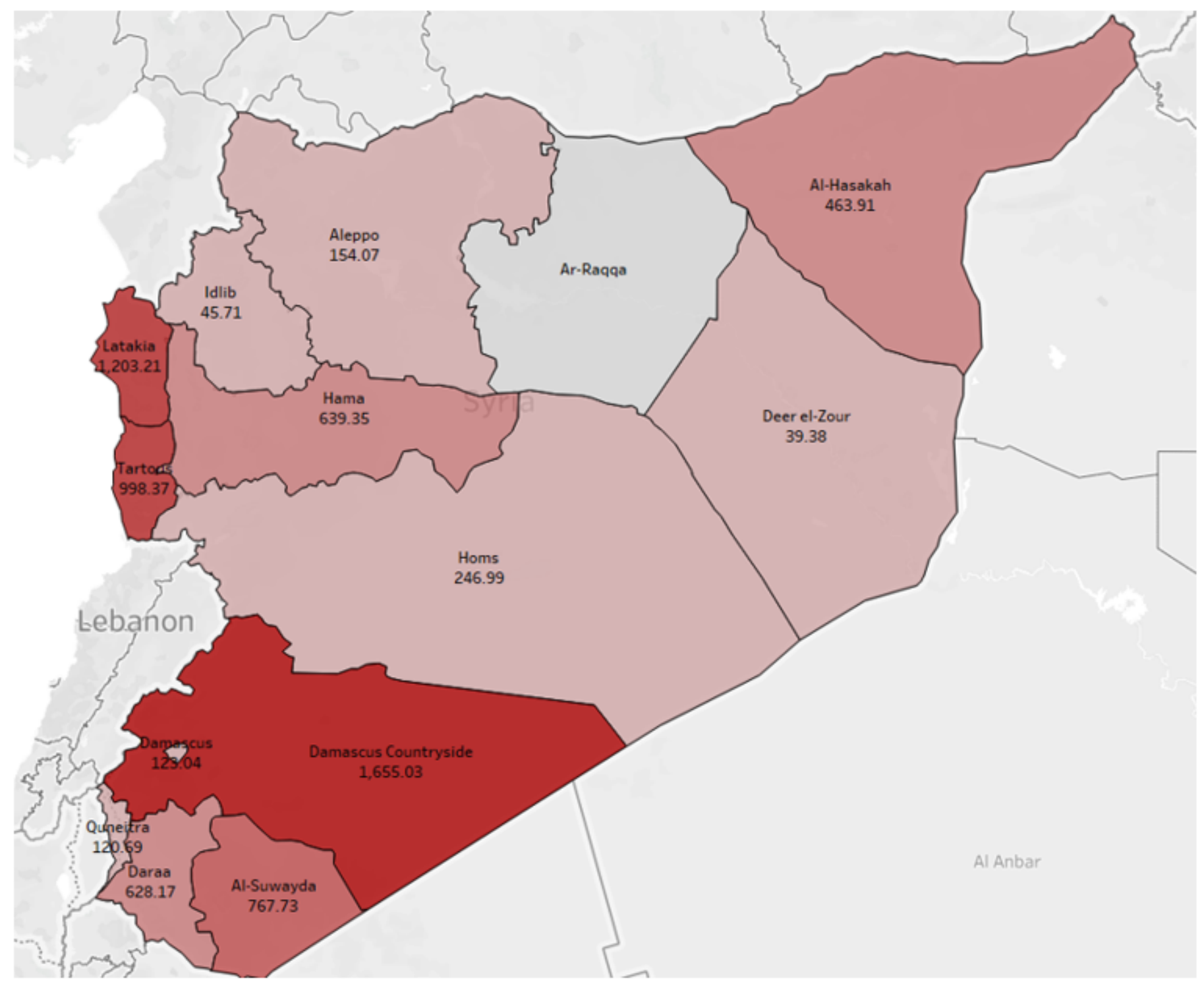

\section{Figure 4}

Adjusted CVDs medicines dispensing rates (DDED) among adults with health insurance in Syria by governorate. 


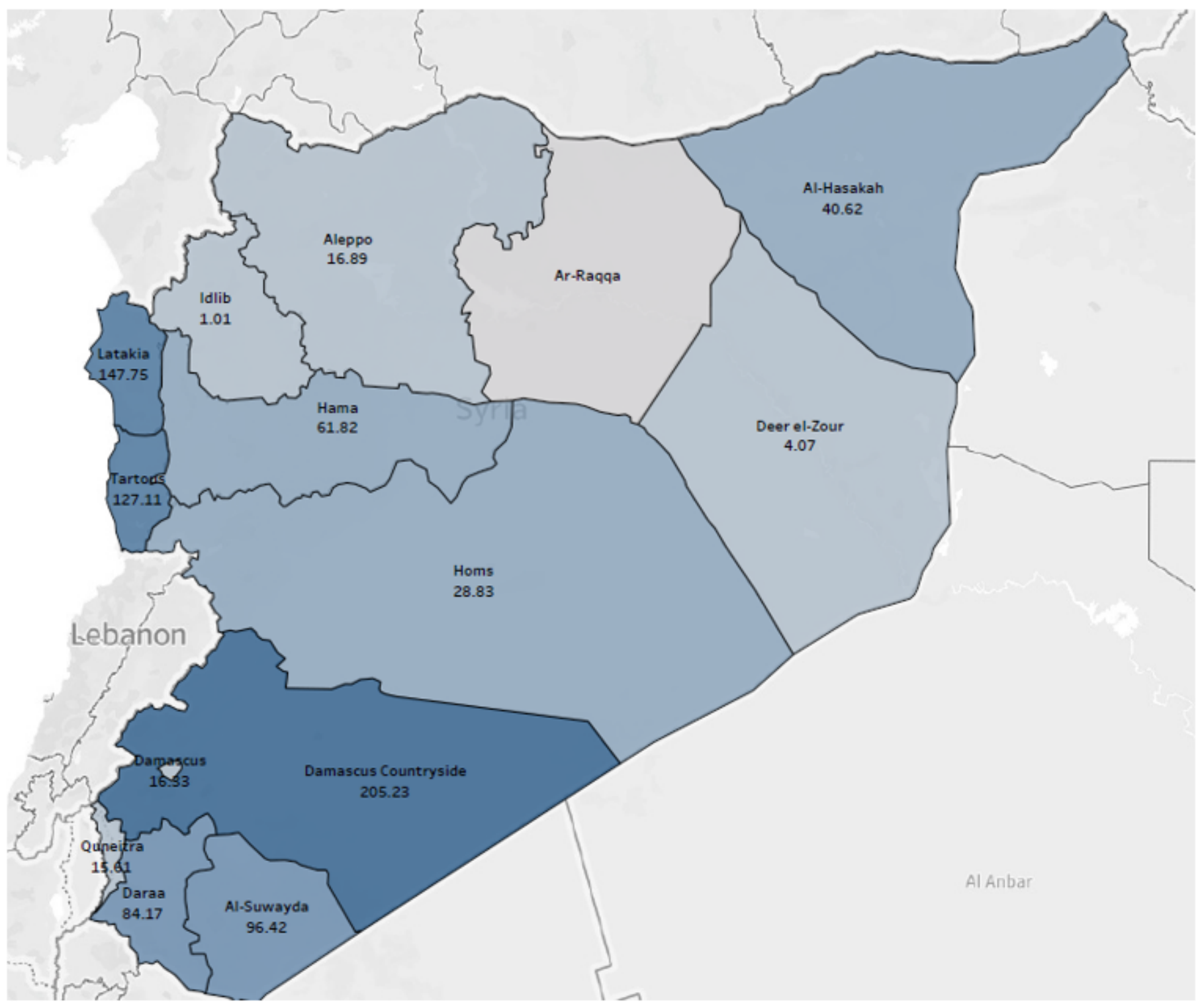

Figure 5

Adjusted diabetes medicines dispensing rates (DDED) among adults with health insurance in Syria by governorate.

\section{Supplementary Files}

This is a list of supplementary files associated with this preprint. Click to download.

- Supplementarymaterial.zip 